\title{
Immunoblot analysis of serological responses in invasive aspergillosis
}

\author{
RUTH MATTHEWS, JP BURNIE, ${ }^{*}$ A FOX, $\dagger$ S TABAQCHALI \\ From St Bartholmew's Hospital Medical School, London, *The London Hospital, and the Public Health \\ Laboratory, Withington Hospital, Manchester
}

SUMMARY The serological response to Aspergillus fumigatus was investigated in patients with pulmonary aspergillosis using the immunoblot technique. Antibody was detected against nine components of the fungus, ranging in molecular weight from 88000 to 33000 daltons. Antibody to a 40000 dalton component was present in most patients ( 13 of 16$)$. In surviving patients it was high (two with aspergilloma)) or low but persistent (two with invasive aspergillosis). It was absent or fell in the 12 patients who died of invasive aspergillosis. Antibody to this $\mathbf{4 0} 000$ dalton antigen was not present in 10 sera from healthy controls. This antigen may form the basis of a more sensitive and specific serodiagnostic test for systemic aspergillosis.

The clinical diagnosis of invasive aspergillosis is difficult, and even when the primary site is pulmonary, examination of sputum is unreliable. ${ }^{1}$ Definitive diagnosis is based on the presence of characteristic hyphae in tissue sections, but patients may be too ill for invasive investigations to be undertaken. Serological tests entailing the detection of aspergillus antibodies are therefore widely used in diagnosis. Many of these patients, however, are immunocompromised and produce poor antibody responses. ${ }^{2}$ Even when highly sensitive techniques such as radioimmunoassay and enzyme linked immunosorbent assay were used about $20 \%$ of cases were missed. ${ }^{34}$ Moreover, $12 \%(7 / 58)$ of patients with other fungal or bacterial infections were positive by radioimmunoassay, ${ }^{3}$ and aspergillus antibodies have been detected in healthy controls by various assay systems. ${ }^{356}$ Thus both the sensitivity and specificity of serodiagnostic tests for invasive aspergillosis need to be improved. To achieve this a better understanding of the various antigenic determinants of aspergillus is required.

We therefore applied the immunoblot technique to the serological response in systemic aspergillosis to identify the key antigens of Aspergillus fumigatus present in these infections. The advantage of this system is that the antibody response to different components of the aspergillus organism can be recorded after separation of the antigens according to their molecular weight. A reference strain of $\boldsymbol{A}$

Accepted for publication 17 July 1985 fumigatus was used together with antigens prepared by mechanical disruption of a young mycelial growth, so that their reproduction would be facilitated. ${ }^{7}$

\section{Material and methods}

Forty nine sera were examined from 16 patients (mean three sera per patient) with pulmonary $A$ fumigatus infections (Table 1). Two of these patients had radiological and cultural evidence of an aspergilloma (one serum sample from each). The remaining 14 had invasive aspergillosis. Their sera were collected after the diagnosis had been made on the basis of histology and culture of pulmonary tissue and were screened at intervals of about two to three days. Twelve of the patients with invasive aspergillosis had lymphoproliferative disorders and were neutropenic. The two other patients were not neutropenic but had sarcoidosis and chronic obstructive airways disease, respectively. Both patients with aspergilloma survived without treatment. Two of the patients with invasive aspergillosis survived, one being treated with itraconazole and the other with amphotericin B. Serum from 10 healthy blood donors was examined as a control.

PREPARATION OF PRESSATE

$A$ fumigatus strain NCPF 2109 was grown at $37^{\circ} \mathrm{C}$ for three days in Sabouraud's broth as described by Mackenzie et al. ${ }^{8}$ The mycelial growth was then harvested, washed, filtered, and passed through a 
Table 1 Summary of clinical details of 16 patients with aspergillosis

\begin{tabular}{llll}
\hline Case No & Diagnosis & Underlying disorders & Outcome \\
\hline $1-2$ & Invasive aspergillosis & LPD, neutropenic & Survived \\
$3-12$ & Invasive aspergillosis & LPD, neutropenic & Died \\
13 & Invasive aspergillosis & Sarcoid and diabetes mellitus & Died \\
14 & Invasive aspergillosis & COAD & Died \\
$15-16$ & Aspergilloma & Pulmonary tuberculosis & Survived \\
\hline
\end{tabular}

LPD = Lymphoproliferative disorder.

COAD = Chronic obstructive airways disease.

Table 2 Distribution of antibody responses to Asperigillus fumigatus

\begin{tabular}{|c|c|c|c|}
\hline Band No & $\begin{array}{l}\text { Molecular weight } \\
\text { (kilodaltons) }\end{array}$ & Recognised by sera from (case No) & Comment \\
\hline 1 & 88 & 10 patients $(1-8,14,15) 3$ controls & $\begin{array}{l}\text { Titres did not correlate with } \\
\text { disease state }\end{array}$ \\
\hline 2 & 63 & 12 patients $\left(1^{*}, 3-11,14,15\right) 2$ controls & $\begin{array}{l}\text { Titres did not correlate with } \\
\text { disease state }\end{array}$ \\
\hline $\begin{array}{l}3 \\
4 \\
5\end{array}$ & $\left.\begin{array}{l}51 \\
49 \\
47\end{array}\right\}$ & $\begin{array}{l}2 \text { patients ( } 5 \text { and } 6) 1 \text { patient recognised } \\
\text { band } 3 \text { only (15) }\end{array}$ & $\begin{array}{l}\text { IgM only: low titre response } \\
\text { (13 mm maximum) }\end{array}$ \\
\hline $\begin{array}{l}6 \\
7 \\
8 \\
9\end{array}$ & $\left.\begin{array}{l}40 \\
37 \\
35 \\
33\end{array}\right\}$ & $\begin{array}{l}13 \text { patients }(1-10,14-16) \\
6 \text { patients }(2,4-6,10,16) \text { recognised } \\
\text { two or three bands; } 3 \text { patients recognised } \\
\text { one of these bands }(7,14,15)\end{array}$ & $\begin{array}{l}\text { (Table 3) } \\
\text { Titres tended to fall as } \\
\text { disease spread }\end{array}$ \\
\hline
\end{tabular}

$*<5 \mathrm{~mm}$ on densitometer scans.

French press at $12 \mathrm{mPa}$ s. It was then centrifuged at $12000 \mathrm{~g}$ for 10 minutes. The supernatant was collected and the protein concentration estimated using the Lowry method. ${ }^{9}$

\section{PREPARATION OF IMMUNOBLOTS}

Immunoblots were prepared as described previously. ${ }^{1011}$ Briefly, the pressate was solubilised in $2.6 \%$ sodium dodecyl sulphate and $1.3 \%$ 2-mercaptoethanol at $100^{\circ} \mathrm{C}$ for five minutes before electrophoresis in $10 \%$ polyacrylamide gel using a discontinuous buffer system. Transfer on to nitrocellulose paper was achieved in a transblotting chamber (Bio-Rad Laboratories, Richmond, California) containing $20 \%$ methanol $25 \mathrm{mM}$ Tris and $192 \mathrm{mM}$ glycine buffer, $\mathrm{pH} 8 \cdot 3$, at $25^{\circ} \mathrm{C}$ using a $350 \mathrm{~mA}$ current for 90 minutes. The nitrocellulose paper was then sliced vertically into strips. Free protein sites were saturated by incubation in $3 \%$ bovine serum albumin in buffered saline $(0.9 \%$ sodium chloride and $10 \mathrm{mM}$ Tris, $\mathrm{pH} \mathrm{7.4)}$ at $4^{\circ} \mathrm{C}$ overnight.

Table 3 Serological responses to band 6 in all 16 patients

\begin{tabular}{ll}
\hline Response & Case No \\
\hline Patients who survived & 1,2 \\
Persisting IgG response $(>5$ weeks $)$ & 16 \\
Major IgM response $(>100 \mathrm{~mm})$ & 15 \\
Major IgG response $(>100 \mathrm{~mm})$ & 3,10 \\
Patients who died & $4-6$ \\
Fading IgM response (twofold or greater fall) & Fading IG response (twofold or greater fall) \\
None or minimal response $(<10 \mathrm{~mm})$ & $7-9,-11-14$ \\
\hline
\end{tabular}

Each strip was then incubated at $25^{\circ} \mathrm{C}$ for two hours with the patient's serum diluted $1 / 10$ with $3 \%$ bovine serum albumin and $0.05 \%$ Tween 20 in buffered saline. After washing five times for 30 minutes in $0.9 \%$ saline and $0.05 \%$ Tween 20 , strips were incubated for one hour at $25^{\circ} \mathrm{C}$ with alkaline phosphatase conjugated goat antihuman IgM or IgG (Sigma). The conjugates were diluted $1 / 1000$ immediately before use in $3 \%$ bovine serum albumin in buffered saline. After washing again, as above, strips were incubated for 15 minutes at $25^{\circ} \mathrm{C}$ with freshly prepared filtered mixtures of equal volumes of naphthol ASMX phosphate (Sigma; 0.4 $\mathrm{mg} / \mathrm{ml}$ in distilled water) and fast red TR salt (Sigma; $6 \mathrm{mg} / \mathrm{ml}$ in $0.2 \mathrm{M}$ Tris, $\mathrm{pH} 8.2$ ). Antigenantibody binding was semiquantified using a densitometer (Chromoscan 3, Joyce Loebl) as discussed by Towbin and Gordon. ${ }^{12}$ Bands on the nitrocellulose strips were correlated with peaks on the densitometry trace of $>5 \mathrm{~mm}$ above background.

\section{Results}

A total of nine bands were obtained with the patients' sera, ranging in molecular weight from 88000 (band 1) to 33000 daltons (band 9) (Table 2). Reactions to band 1 ( 88000$)$ were obtained with the sera from 10 of the 16 patients and three of the 10 control subjects. Sera from 12 of the patients and two of the controls reacted with band 2 (63000 daltons). None of the remaining bands was recognised by the control sera. 


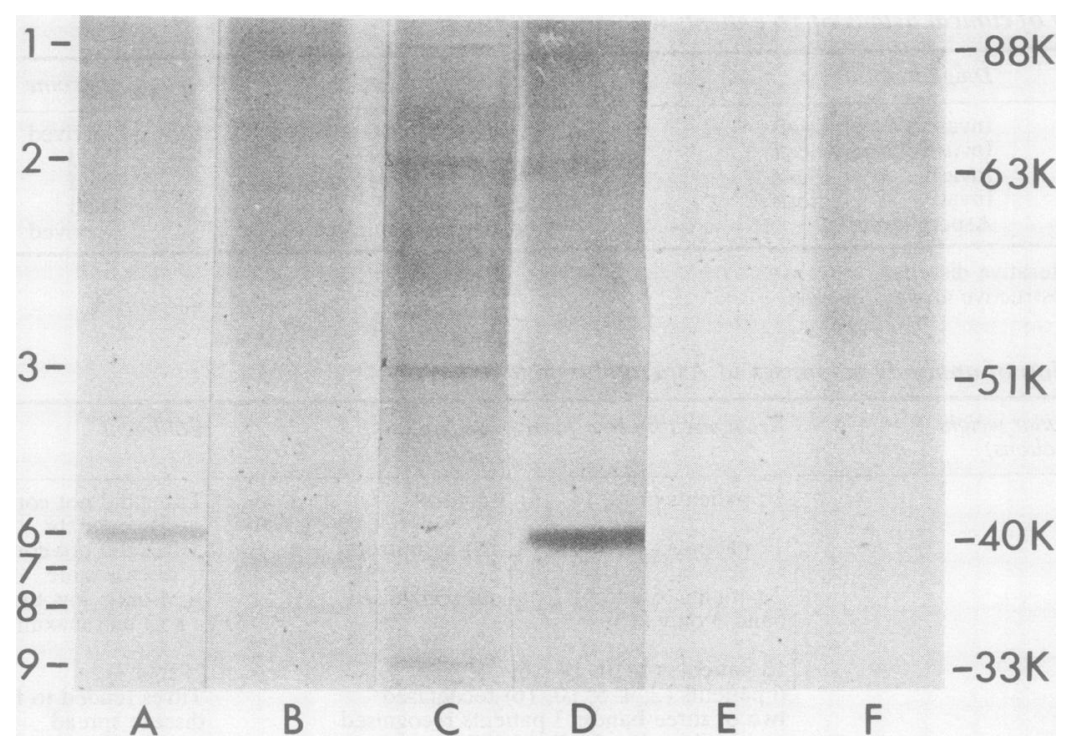

Immunoblots of $A$ fumigatus against the following patient's sera: $(A)$ case 16 IgM; $(B)$ case $16 \mathrm{IgG}$; (C) case $15 \mathrm{IgM}$; (D) case $15 \mathrm{IgG} ;(E)$ case $1 \mathrm{IgM} ;(F)$ case $1 \mathrm{IgG}$. Band numbers indicated on left, molecular weights (kilodaltons) on right.

The third commonly recognised antigen was that of 40000 daltons (band 6). This was detected by sera from 13 patients (Table 2). Bands 7,8 , and 9 ( 37000,35000 , and 33000 daltons) tended to be recognised as a cluster (six patients), but occasionally only one of these bands would be recognised (three patients) (Table 2). Similarly, bands 3, 4, and 5 (51000, 49000 , and 47000 daltons) occasionally occurred as a cluster (two patients). None of these bands was recognised by the control sera (Table 2).

The antibody titres produced to the above bands were all less than $40 \mathrm{~mm}$, as determined by the densitometer scans. In contrast, the antibody response produced to band 6 (40000 daltons) was greater than $100 \mathrm{~mm}$ in the two patients with aspergilloma (Table 3 ; Figure). One of these patients (case 15) produced an IgG response of $170 \mathrm{~mm}$ to band 6 and a small amount of IgM to bands 1, 2, 3, and 9 (up to $12 \mathrm{~mm}$ ). The other (case 16) had an IgM response of $110 \mathrm{~mm}$ to band 6 and low titres $(<12 \mathrm{~mm})$ of $\mathrm{IgG}$ to bands 6,7 , and 8 . In the 12 patients who died of invasive aspergillosis the antibody response to band 6 was either very low or absent (seven patients) or faded to half its initial titre in subsequent terminal sera (five patients) (Table 3). Two patients with invasive aspergillosis survived. In one of these (case 1) the antibody response to band 6 was relatively low $(15 \mathrm{~mm} \mathrm{IgG}$ and $10 \mathrm{~mm}$ IgM) (Figure) but persisted for five weeks, during which time the patient gradually responsed to itraconazole. It was only after this patient had made a clinical recovery, confirmed by a second bronchial biopsy that was now negative, that the antibody faded. The second patient (case 2 ) had recovered from invasive aspergillosis three months earlier and still had trace amounts (less than $10 \mathrm{~mm}$ ) of antibody to bands $1,6,7$, and 8 .

\section{Discussion}

The immunoblot technique showed that patients with pulmonary aspergillosis produce antibody against a total of nine components of $\boldsymbol{A}$ fumigatus, ranging in molecular weight from 88000 to 33000 daltons. The most clinically important band was that of 40000 daltons (band 6). Antibody to this band was detectable in 13 of the 16 patients but none of the healthy controls. The two patients with noninvasive aspergilloma produced high titres (110 and $170 \mathrm{~mm}$ ) of antibody to band 6 and low titres (12 $\mathrm{mm}$ or less) to other bands. In one patient (case 15) this was of the IgG class. In another patient (case 16) it was mainly IgM but there was some IgG, suggesting that this patient was in the process of seroconverting to the $\mathbf{4 0 0 0 0}$ dalton band. All the patients with invasive aspergillosis produced much less antibody to band 6 (maximum IgG $24 \mathrm{~mm}$ (case 4); maximum IgM $40 \mathrm{~mm}$ (case 10)). In five cases the antibody titre fell as the patients' condition deteriorated, and in seven patients antibody to band 
6 was undetectable or present in only trace amounts $(<10 \mathrm{~mm})$. All these patients died. Two patients, however, who developed invasive aspergillosis while neutropenic, eventually recovered. Both had evidence of a low but persistent antibody response to band 6 .

Twelve of the patients were neutropenic and had lymphoproliferative disorders. Two of the patients with invasive aspergillosis (cases 13 and 14), however, were not obviously immunocompromised but had little antibody to the aspergillus antigens $(<20 \mathrm{~mm})$. Similarly, Young and Bennett, using double diffusion, complement fixation, or indirect immunofluorescence, found a patient with invasive aspergillosis who had aplastic anaemia and had not received immunosuppressive treatment but who, nevertheless did not have detectable aspergillus antibody. ${ }^{2}$ They suggested that patients with widespread invasive disease mount a poor antibody response to the fungus.

Bands 1 ( 88000 daltons) and 2 (63000 daltons) were recognised by sera from most of the patients but also by sera from some of the healthy controls, band 1 being recognised by 10 patients and three controls and band 2 by 12 patients and two controls. The titres of antibody produced to these bands by the patients did not correlate with the course of their infections. Others have found antibody detectable in controls in whom sufficiently sensitive assay systems have been used. ${ }^{356}$ In a recent study in which 11 fractions of $\boldsymbol{A}$ fumigatus were prepared healthy controls had antibodies against seven of these..$^{13}$ Such antibodies probably reflect the ubiquitous nature of $A$ fumigatus, as well as its ability to cross react antigenically with other common fungi such as candida. ${ }^{14}$

Bands 1 and 2 would be unsuitable as the basis of a serodiagnostic test because, although recognised by most patients, they are also detected by some healthy controls. Bands 3-5 and 7-9, although not recognised by healthy controls, were detected by only a few patients. Antibody to the $\mathbf{4 0 0 0 0}$ dalton band 6 , however, was present in most patients (13/ 16); titres varied with the course of the infections and antibody to this antigen was not detectable in healthy controls.

In conclusion, it seems that the amount of antibody induced by invasive aspergillosis is relatively low compared with that in aspergilloma, and the titres produced against some antigens actually decline as the disease becomes more advanced. This imposes a severe limitation on serodiagnostic tests based on antibodies. If more sensitive assay systems are developed false positive results may occur, although there is some evidence that these might be removed if specific antigen fractions are used. The future lies in tests based on antigen, which are not dependent on the production of antibody. A radioimmunossay for detecting antigens has been described, ${ }^{15}$ but this was positive in only four of seven patients with systemic aspergillosis. Purification of the 40000 dalton antigen may help us to develop such a test as immunoblot analysis of the serological response suggests that this is a key antigen in the pathogenesis of invasive aspergillosis.

We thank the Christie Institute, Manchester, and Dr AJ Prentice, Derriford Hospital, Plymouth, for sera.

\section{References}

' Young RC, Bennett JE, Vogel CL, Carbone' PP, de Vita VT. Aspergillosis. The spectrum of disease in 98 patients. Medicine 1970; 49:147-73.

${ }^{2}$ Young RC, Bennett JE. Invasive aspergillosis. Absence of detectable antibody response. Am Rev Respir Dis 1971; 104:710-6.

${ }^{3}$ Marier R, Smith W, Jansen M, Andriole VT. A solid-phase radioimmunoassay for the measurement of antibody to aspergillus in invasive aspergillosis. $J$ Infect Dis 1979; 140:771-9.

${ }^{4}$ Holmberg K, Berdischewsky M, Young LS. Serologic immunodiagnosis of invasive aspergillosis. J Infect Dis 1980; 141:656-64.

s Gold JWM, Fisher B, Yu B, Chein N, Armstrong D. Diagnosis of invasive aspergillosis by passive haemagglutination assay of antibody. J Infect Dis 1980;142:87-94.

- Gordon MA, Lapa EW, Kane J. Modified indirect fluorescentantibody test for aspergillosis.J Clin Microbiol 1977;6:161-5.

${ }^{7}$ Hearn VM, Wilson EV, Proctor AG, Mackenzie DWR. Preparation of Aspergillus fumigatus antigens and their analysis by two dimensional immunoelectrophoresis. J Med Microbiol 1980;13:451-8.

B Mackenzie DWR, Philpot CM, Proctor AG. Basic serodiagnostic methods for diseases caused by fungi and actinomycetes. Public Health Laboratory Service Monograph Series 1980; No 12.

' Lowry OH, Rosebrough NJ, Farr AL, Randall RJ. Protein measurement with the folin phenol reagent. J Biol Chem 1951;193:265-75.

${ }^{10}$ Matthews RC, Burnie JP, Tabaqchali S. Immunoblot analysis of the serological response in systemic candidosis. Lancet 1984;ii: $1415-8$.

" Burnie JP, Matthews RC, Fox A, Tabaqchali S. Use of immunoblotting to identify antigenic differences between the yeast and mycelial phases of Candida albicans. J Clin Pathol 1985; 38:701-6.

12 Towbin H, Gordon J. Immunoblotting and dot immunobinding - current status and outlook. J Immunol Methods 1984;72:313-40.

${ }^{13}$ Schønheyder H, Anderson P. Fractionation of Aspergillus fumigatus antigens by hydrophobic interaction chromatography and gel filtration. Int Arch Allergy Appl Immunol 1984; 73:231-6.

14 De Magaldi SW, Mackenzie DWR. Specificity of antigens from pathogenic Aspergillus species I. Studies with ELISA and immunofluorescence. Sabouraudia 1984;22:381-94.

is Weiner MH. Antigenaemia detected by radioimmunoassay in systemic aspergillosis. Ann Intern Med 1980;92:793-6.

Requests for reprints to: Dr Ruth Matthews, Department of Medical Microbiology, St Bartholomew's Hospital, West Smithfield, London EC1A 7BE, England. 